Science, Technology and Development 34 (1): 52-59, 2015

ISSN 0254-6418 / DOI: 10.3923/std.2015.52.59

(C) 2015 Pakistan Council for Science and Technology

\title{
Antidiarrheal, Antispasmodic and Bronchodilator Activities of Pistacia integerrima are Mediated through Dual Inhibition of Muscarinic Receptors and $\mathbf{C a}^{++}$Influx
}

\author{
${ }^{2}$ Khalid Hussain Janbaz, ${ }^{1,2}$ Waseem Hassan, ${ }^{1}$ Malik Hassan Mehmood and ${ }^{1,3}$ Anwarul-Hassan Gilani \\ ${ }^{1}$ Natural Product Research Division, Department of Biological and Biomedical Sciences, \\ The Aga Khan University Medical College, 74800, Karachi, Pakistan \\ ${ }^{2}$ Faculty of Pharmacy, Bahauddin Zakariya University, 60800, Multan, Pakistan \\ ${ }^{3}$ Pakistan Council for Science and Technology, Shahra-e-Jamhuriat, G-5/2, Islamabad, Pakistan
}

\begin{abstract}
Pistacia integerrima (J. L. Stewart ex Brandis) is native plant to this region and has a history of vernacular use in gastrointestinal and respiratory tract disorders. This study was aimed to validate native therapeutic utility of $P$. integerrima in gut and airway diseases using the in-vivo and in-vitro assays. Oral administration of the crude methanolic extract of $P$. integerrima (Pi.Cr) to mice provided protection against castor oil-induced diarrhea, similar to the effect of loperamide and was also found safe without any symptoms of acute toxicity or lethality up to the maximum tested dose of $9 \mathrm{~g} \mathrm{~kg}^{-1}$. When tested in isolated tissues preparations, Pi.Cr potently inhibited spontaneous contractions in rabbit jejunum, while it also caused complete relaxation of high $\mathrm{K}^{+}(80 \mathrm{mM})$ and carbachol $(\mathrm{CCh}, 1 \mu \mathrm{M})$-induced contractions both in jejunal and tracheal preparations being more potent against CCh. Pretreatment of tissues with Pi.Cr, at low dose, caused a parallel shift in CCh Concentration-Response Curves (CRCs) without suppression of the maximal response but further increase in dose, caused a non-parallel shift with suppression of maximal response, similar to the effect of dicyclomine. The study concludes that $P$. integerrima possesses antidiarrheal, antispasmodic and bronchodilator activities possibly mediated through dual inhibition of muscarinic receptors and $\mathrm{Ca}^{++}$influx, thus providing scientific basis to the folk medicinal use of $P$. integerrima in gut (diarrhea) and airways (asthma and bronchitis) disorders.
\end{abstract}

Key words: Pistacia integerrima galls, antidiarrheal, bronchodilator, antispasmodic, muscarinic receptor antagonist, $\mathrm{Ca}^{++}$channel antagonist

\section{INTRODUCTION}

Pistacia integerrima (J. L. Stewart ex Brandis) (Syn: Pistacia chinensis; Family: Anacardiaceae) is locally known as Kakarsinghi (Usmanghani et al., 1997). It is a single stemmed, multi-branched high tree of deciduous nature found in northern hilly areas of Pakistan (Nadkarni, 1986). The galls of the plant have been used traditionally to treat cough, vomiting, asthma, fever, anorexia and gastric irritation (Pant and Samant, 2010). The high tannins contents of galls enable it to be used in combination in the management of diarrhea particularly infantile diarrhea and other gut disorders during teething (Nadkarni, 1986). The galls are also considered useful in pulmonary affections (Usmanghani et al., 1997).

Phytochemical investigations of the galls of $P$. integerrima yielded phytochemicals characterized as ndecan 3-ol-yl-n-eicosanoate, n-octadecan-9, 11-diol-7-one

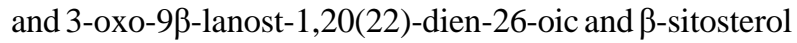
(Ahmad et al., 2010a), flavonoids, Anthraquinone, alkaloids, steroids, tannins and Anthocyanin (Uddin and
Rauf, 2012). In addition, pistagremic acid, a novel triterpene has also been determined as plant constituent (Uddin et al., 2012a).

The scientific investigation on plant material and its isolated compounds for its biological activities revealed that it possesses leishmanicidal (Uddin et al., 2012a), glucosidase inhibitory (Uddin et al., 2012b), antibacterial and anti-fungal (Uddin and Rauf, 2012; Aqil and Ahmed, 2003), analgesic and anti-inflammatory (Ahmad et al., 2010b; Ansari and Ali, 1996) and anti-gout (Ahmad et al., 2008) activities along with its positive influence on central nervous system (Ansari et al., 1993).

$P$. integerrima has been used traditionally in the treatment of a number of ailments including diarrhea and asthma; however, to the best of our knowledge, there is no study available in the literature supporting its folk medicinal uses in diarrhea or asthma. This study has been designed to provide pharmacological basis to its medicinal use in hyperactive gut disorders such as diarrhea and spasm and airways sensitivity such as asthma, using the in-vivo assays and isolated tissue experiments.

Corresponding Author: Anwarul-Hassan Gilani, Pakistan Council for Science and Technology, Shahra-e-Jamhuriat, G-5/2, Islamabad, Pakistan Tel: +92-51-9204416 Fax: 9222172 


\section{MATERIALS AND METHODS}

Preparation of the crude extract: The galls of leaves of $P$. integerrima were purchased from a herbal store in Multan and rendered them free of adulterated material. The plant material was identified by an expert taxonomist, Prof. Mumtaz Hussain Bukhari, Institute of Pure and Applied Biology, Bahauddin Zakariya University, Multan. A specimen voucher \# PI-G-06-09-121, was preserved in the herbarium of the Natural Product Research Division, Department of Biological and Biomedical Sciences, the Aga Khan University, Karachi. The plant leaves were ground into coarse powder through electrically driven device. The powdered material was soaked in $80 \%$ aqueous-methanol (v/v) for eight days in amber colored glass bottles with gentle shaking on alternate days. The soaked materials was passed through muslin cloth to remove vegetative debris followed by pressing of marks. The obtained fluid was subjected to filtration through Wattman grade No.1 filter paper and evaporated to get thick pastes using rotary evaporator under reduced pressure at $37^{\circ} \mathrm{C}$ followed by freeze drying of thick paste material into dry form. The practical yield of $P$. integerrima extract was $9.13 \% \mathrm{w} / \mathrm{w}$ and it was found soluble in distilled water.

Chemicals: Acetylcholine, atropine sulphate, carbachol, dicyclomine, calcium chloride, potassium chloride and loperamide hydrochloride were purchased from Sigma Chemicals Co, St Louis, MO, USA. Castor oil was purchased from Karachi chemical industries (Pvt.) Ltd. F/25 S. I. T. E., Karachi (Pakistan). All chemicals used were of the analytical grade available and solubilized in distilled water/saline. Stock solutions of all chemicals were prepared fresh on the day of the experiment.

Animals: BALB/c mice (weighing 20-25 g) and locally bred rabbits (weighing 1-1.5 kg) of either sex, were housed at the Animal House of Aga Khan University under controlled environmental conditions $\left(23-25^{\circ} \mathrm{C}\right)$. The animals were fasted for 16-18 h before the experiment, whereas they were given tap water and standard diet routinely. Experiments were performed with the rulings of the Institute of Laboratory Animal Resources, Commission on Life Sciences, National Research Council (NRC., 1996). This study (77/2007-Pharm/BZU) was the part of the M.Phil thesis of Mr. Waseem Hassan which was approved by the Board of Studies, Bahauddin Zakariya University, Multan.

\section{In-vivo assays}

Antidiarrheal activity: Mice (20-25 g, $n=20)$ of either sex were fasted for 16-18 $\mathrm{h}$ before the experiment. The animals were housed in individual cages and divided in 4 groups, for each $n=5$. The first group received saline along with solubilizing vehicle $\left(10 \mathrm{~mL} \mathrm{~kg}^{-1}\right.$, orally), acted as negative control. The second group received loperamide (10 mg kg-1) orally, serving as positive control. The remaining two groups received 700 and $900 \mathrm{mg} \mathrm{kg}^{-1}$ doses of the crude extract of $P$. integerrima, respectively. After $1 \mathrm{~h}$ of the respective treatments, each animal received $10 \mathrm{~mL} \mathrm{~kg}^{-1}$ castor oil orally through a feeding needle. After $5 \mathrm{~h}$, the cages were inspected for the presence of typical diarrheal droppings; the absence was regarded as a positive result, indicating protection from diarrhea (Mehmood et al., 2011).

Acute toxicity testing: A total of 20 mice (20-25 g) of either sex were equally divided into four groups. The test was performed using increasing doses of the crude extract of the $P$. integerrima (1, 3 and $9 \mathrm{~g} \mathrm{~kg}^{-1}$ ) given orally in $10 \mathrm{~mL} \mathrm{~kg}^{-1}$ control vehicle to different animals serving as the test groups. Another group of mice was administered control vehicle $\left(10 \mathrm{~mL} \mathrm{~kg}{ }^{-1}\right)$ orally as the negative control. The animals were allowed food and water ad libitum and kept under regular observation for 6 h to observe any acute toxicity symptoms such as, piloerection, changes in exploratory behavior and blindness, while lethality was monitored up to $24 \mathrm{~h}$.

\section{In-vitro Experiments}

Spasmolytic activity: The spasmolytic activity of the test material was studied by using isolated rabbit jejunum preparations (Mehmood and Gilani, 2010). The rabbits of either sex of local breed were used. The animals were subjected to starvation for $24 \mathrm{~h}$ prior to the euthanasia. Laparotomy was carried out, segments of jejunum approximately $2-3 \mathrm{~cm}$ in length were removed. Isolated jejunum strips were suspended individually in $10 \mathrm{~mL}$ tissue baths containing Tyrode's solution, aerated with a mixture of $95 \%$ oxygen and $5 \%$ carbon dioxide (carbogen) and maintained at $37^{\circ} \mathrm{C}$ using thermocirculator. The composition of the Tyrode's solution in mM was: $\mathrm{KCl} 2.68, \mathrm{NaCl} 136.9, \mathrm{MgCl}_{2} 1.05$, $\mathrm{NaHCO}_{3}$ 11.90, $\mathrm{NaH}_{2} \mathrm{PO}_{4}$ 0.42, $\mathrm{CaCl}_{2} 1.8$ and glucose 5.55 (pH 7.4). Intestinal responses were recorded isotonically using Bioscience Transducers coupled with PowerLab data acquisition system (ADInstruments, Sydney, Australia). Each tissue was allowed to equilibrate for at least 30 min before the addition of any drug and then stabilized with a sub-maximal concentration of acetylcholine (ACh, $0.3 \mu \mathrm{M}$ ) and the bath fluid was subsequently replaced with normal Tyrode's solution before starting the experiment.

The myorelaxant effect of the crude extract of $P$. integerrima was assessed on spontaneously contracting isolated rabbit jejunum. For elucidation of the possible mechanism of spasmolytic effect, carbachol (CCh, $1 \mu \mathrm{M}$ ) and high $\mathrm{K}^{+}(80 \mathrm{mM})$ were used to induce sustained contractions mediated through different mechanisms, thus 
allowing to study spasmolytic effect. Both spasmogens are considered useful for determining the different inhibitory mechanisms of test material like, antimuscarinic (Mehmood et al., 2011; Gilani et al., 2005) or $\mathrm{Ca}^{++}$antagonist (Gilani et al., 2007), respectively. The test material was then added in a cumulative fashion to obtain concentration-dependent inhibitory response curves. The relaxation of isolated tissue preparations was expressed as percent of the control response mediated by added $\mathrm{CCh}$ or high $\mathrm{K}^{+}$-induced concentrations. To further confirm antimuscarinic and $\mathrm{Ca}^{++}$antagonist like activities in the test material, CCh concentration-response curves (CRCs) were constructed in the presence and absence of different doses of test material to observer its impact on control curves of CCh, whether the test material produces parallel shift without suppression of maximum response, a typical characteristic of antimuscarinic agent or non-parallel shift with suppression of maximum response, characteristic behavior of $\mathrm{Ca}^{++}$antagonist (Gilani et al., 2005).

Bronchodilator activity: The bronchodilator activity of the test material was studied by using isolated tracheal preparations (Mandukhail et al., 2014) from rabbits of either sex of local breed. The animals were subjected to starvation for 16-18 h prior to the euthanasia. Rabbit tracheal tube was dissected out and immersed in of physiologic Kreb's solution at $37^{\circ} \mathrm{C}$ bubbled with carbogen. Respective rings were prepared and mounted in tissue baths. A fixed preload of $1 \mathrm{~g}$ was applied to the tracheal rings and they were allowed to equilibrate in this state for about $45 \mathrm{~min}$. $\mathrm{CCh}$ and high $\mathrm{K}^{+}$were used to produce contraction of tissues until reproducible responses were recorded. CCh was added to different tissues to produce sustained contraction and thereafter, the test material was applied in a cumulative fashion to assess the presence of bronchodilatory effects against any of these spasmodic agents. Dicyclomine was used to relax $\mathrm{CCh}$ and high $\mathrm{K}^{+}$-induced contractions and served as positive control. In order to construct CRCs, CCh was applied in graded concentrations to induce contractile response curve. Thereafter, the control CRCs of CCh were reproduced in the presence of increasing doses of the test material and dicyclomine, to observe the presence of antimuscarinics and/or $\mathrm{Ca}^{++}$antagonist like activity (Gilani et al., 2005; Khan et al., 2012; Janbaz et al., 2012).
Statistical analysis: All the data expressed are Mean \pm standard error of mean (SEM, $n=$ No. of experiments) and the median effective concentrations (EC ${ }_{50}$ values) with 95\% confidence intervals (CI). The concentration-response curves were analyzed by non-linear regression (Graph-PAD program, Graph-PAD, San Diego, CA, USA). The Chi-square-test was applied to differentiate the results of antidiarrheal activity. Probability of less than 0.05 was considered significantly different.

\section{RESULTS}

\section{In-vivo assays}

Effect on castor oil-induced diarrhea in mice: Oral administration of $P$. integerrima exhibited a dosedependent inhibitory effect against castor oil-induced diarrhea in mice by producing 40 and $60 \%$ protection at respective doses of 700 and $900 \mathrm{mg} \mathrm{kg}^{-1}$. The positive control, loperamide produced $100 \%$ protection at the dose of $10 \mathrm{mg} \mathrm{kg}^{-1}$, while the group administered only saline plus castor oil only showed minor protection against diarrhea in mice as shown in Table 1.

Acute toxicity test: The plant extract was well tolerated by the animals up to the highest tested oral dose of as high as $9 \mathrm{~g} \mathrm{~kg}^{-1}$. No sign of acute toxicity like restlessness, seizures or piloerection were observed over the period of observation (6 h) and there was no death recorded up to $24 \mathrm{~h}$.

\section{In-vitro assays}

Effect on rabbit jejunum: The crude extract of $P$. integerrima inhibited spontaneous contractions in rabbit jejunum with $\mathrm{EC}_{50}$ value of $1.26 \mathrm{mg} \mathrm{mL}^{-1}$ (0.972.35, 95\% CI, $n=4$ ) as shown in Fig. 1a. In spasmogeninduced contractions, the plant extract was found more potent in its inhibitory effect against CCh-induced contractions with respective $\mathrm{EC}_{50}$ value of $0.05 \mathrm{mg} \mathrm{mL}^{-1}$ $(0.02-0.09, \mathrm{n}=5)$ compared to its effect against high $\mathrm{K}^{+}$ [1.29 $\left.\mathrm{mg} \mathrm{mL}^{-1}(1.02-2.79, \mathrm{n}=5)\right]$ as shown in Fig. $1 \mathrm{~b}$. Similarly, the positive control, dicyclomine potently relaxed CCh-induced contraction with respective $\mathrm{EC}_{50}$ value of $0.29 \mu \mathrm{M}(0.25-0.39, \mathrm{n}=4)$, when compared to its effect that obtained against spontaneous and high $\mathrm{K}^{+}$-induced contractions with respective $\mathrm{EC}_{50}$ values of $0.97 \mu \mathrm{M}(0.68-1.55, \mathrm{n}=4)$ and $16.11 \mu \mathrm{M}$ (14.23-20.57, $\mathrm{n}=6)$.

Table 1: Antidiarrheal effect of the crude extract of Pistacia integerrima (Pi.Cr) against castor oil $\left(10 \mathrm{~mL} \mathrm{~kg}^{-1}\right)$-induced diarrhea in mice

\begin{tabular}{lcccc}
\hline Treatment (per oral) & Dose $\left(\mathrm{mg} \mathrm{kg}^{-1}\right)$ & Total no. of mice/group & No. of mice with diarrhea after 5 h & Protection (\%) \\
\hline Saline+Castor oil & $10+10$ & 5 & 4 & 20 \\
Loperamide+Castor oil & 10 & 5 & 0 & 100 \\
Pi.Cr+Castor oil & $700+10$ & 5 & 3 & 40 \\
Pi.Cr+Castor oil & $900+10$ & 5 & 2 & 60 \\
\hline
\end{tabular}


Sci. Technol. Dev., 34 (1): 52-59, 2015
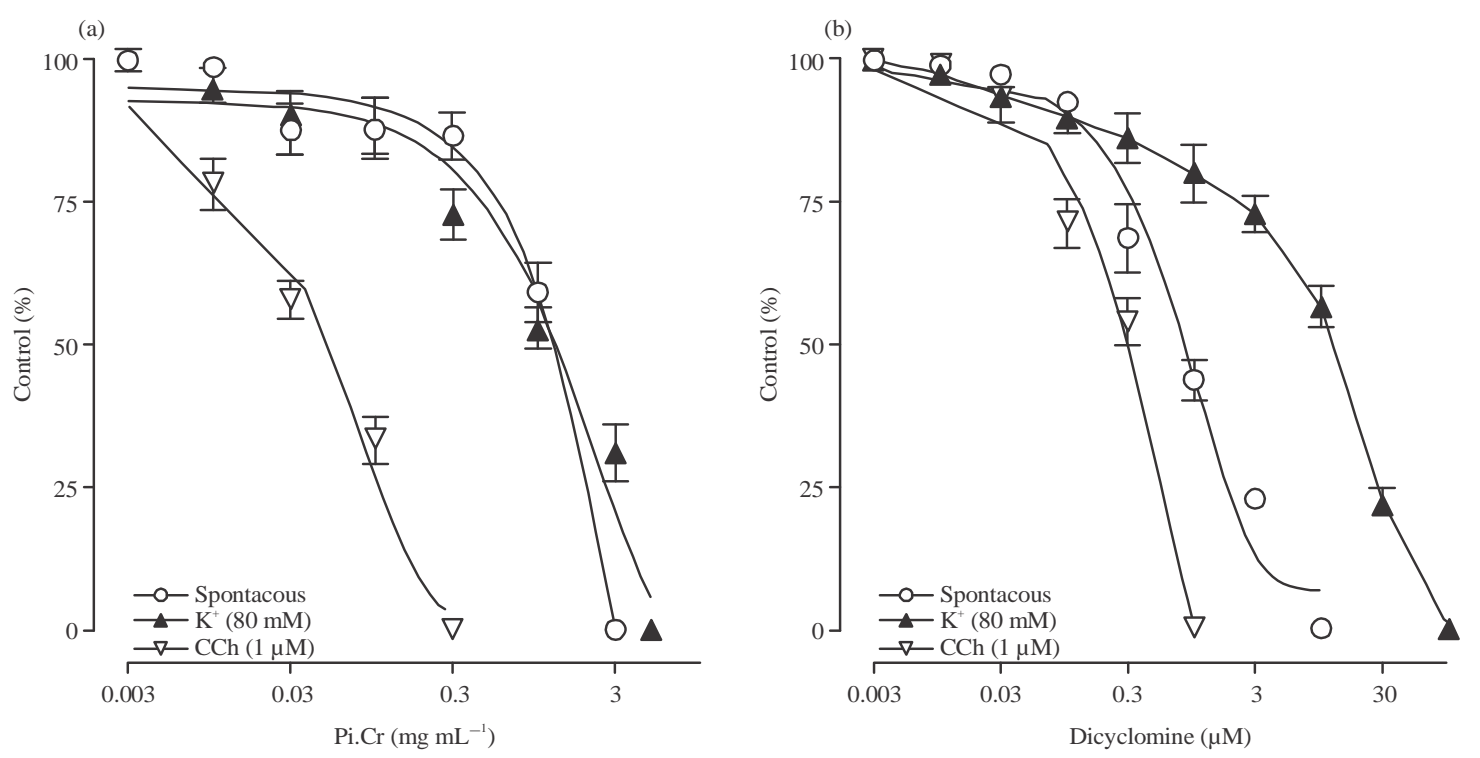

Fig. 1(a-b): Concentration-dependent inhibitory effect of (a) Crude extract of $P$. integerrima (Pi.Cr) and (b) Dicyclomine against spontaneous, carbachol $(\mathrm{CCh}, 1 \mu \mathrm{M})$ and high $\mathrm{K}^{+}(80 \mathrm{mM})$-induced contractions in isolated rabbit jejunum preparations. Values represent Mean \pm SEM data of 4-6 individual experiments
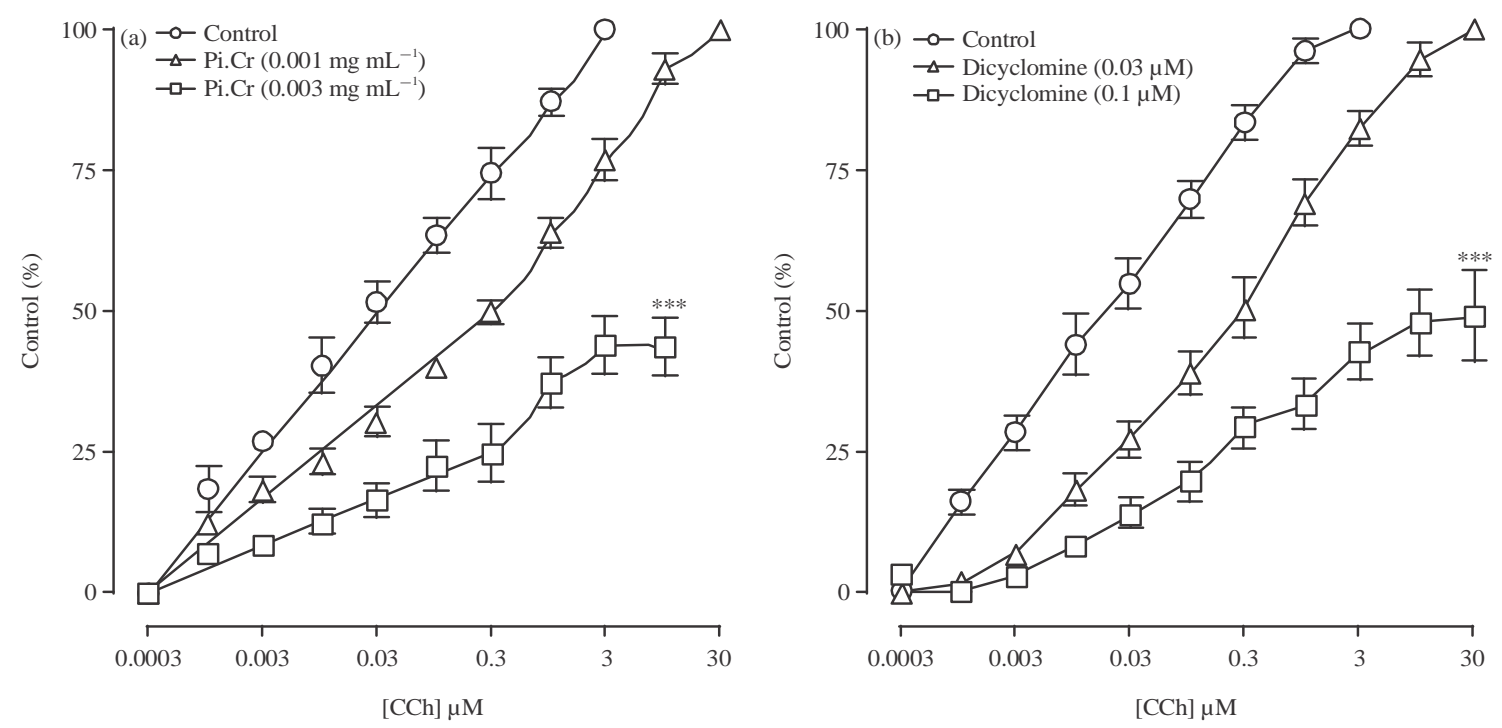

Fig. 2(a-b): Concentration-response curves of $\mathrm{Ca}^{++}$in the absence and presence of increasing doses of (a) Crude extract of $P$. integerrima (Pi.Cr) and (b) Dicyclomine in isolated rabbit jejunum preparations. Values are expressed as Mean \pm SEM, $n=4-5$

Pretreatment of jejunum tissues with the plant extract at $0.001 \mathrm{mg} \mathrm{mL}^{-1}$ caused a rightward parallel shift in the control CRCs of CCh, without suppression of the maximum contractile response, a typical characteristic of competitive blocker (Arunlakshana and Schild, 1959). However, at the next higher concentration $\left(0.003 \mathrm{mg} \mathrm{mL}^{-1}\right)$, P. integerrima extract produced a nonparallel shift with suppression of the maximum response $(60.01 \pm 8.2 \%$ versus $100 \%)$ as shown in Fig. 2a. Similarly, dicyclomine shifted the CRCs of CCh to the right in a parallel manner without suppression of the maximum response at a lower dose $(0.03 \mu \mathrm{M})$, while at next higher concentration of $0.1 \mu \mathrm{M}$, it caused a rightward but non-parallel shift in the CCh curves with a marked suppression of the maximum effect $(52.98 \pm 9.70 \%)$ as shown in Fig. $2 b$.

Effect on rabbit trachea: In isolated rabbit tracheal preparations, $P$. integerrima extract caused relaxation of 
CCh and high $\mathrm{K}^{+}$-induced bronchoconstriction, being more potent against $\mathrm{CCh}$ contractions with respective $\mathrm{EC}_{50}$ value of $0.67 \mathrm{mg} \mathrm{mL}^{-1}(0.31-0.98, \mathrm{n}=5)$ compared to that [2.59 $\left.\mathrm{mg} \mathrm{mL}^{-1}(2.11-3.30, \mathrm{n}=5)\right]$ on high $\mathrm{K}^{+}$as shown in Fig. 3a. Dicyclomine was also more potent in terms of causing bronchodilatation against CCh-induced bronchoconstriction with respective $\mathrm{EC}_{50}$ value of $0.71 \mu \mathrm{M}(0.34-1.20, \mathrm{n}=6)$ compared to its effect against $\mathrm{K}^{+}$with respective $\mathrm{EC}_{50}$ value of $18.40 \mu \mathrm{M}$ (16.29-23.19, $\mathrm{n}=4)$ ] as shown in Fig. 3b.

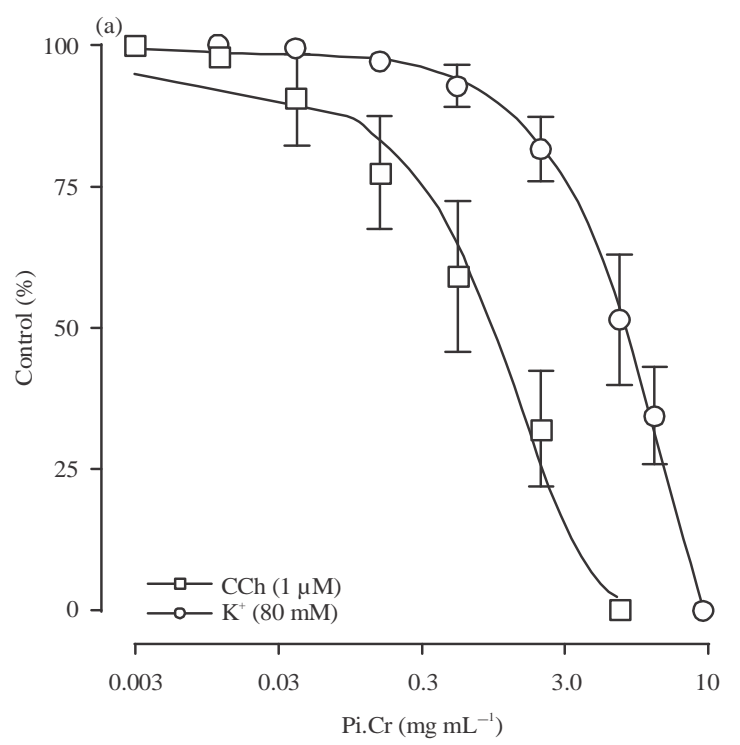

To see, if plant extract interacts at the muscarinic receptors, tissues were pretreated with plant extract $\left(0.003 \mathrm{mg} \mathrm{mL}^{-1}\right)$, which caused a rightward parallel shift in the control CRCs of CCh and the maximum contractile response remained unaltered, whereas, at the next higher dose of $0.01 \mathrm{mg} \mathrm{mL}^{-1}$, the plant extract produced a non-parallel shift with suppression of the maximum response $(38 \pm 7.6 \%, \mathrm{n}=3$ versus $100 \%)$ as shown in Fig. 4a. Similarly, dicyclomine shifted the CRCs of CCh to the right in a parallel manner without suppression

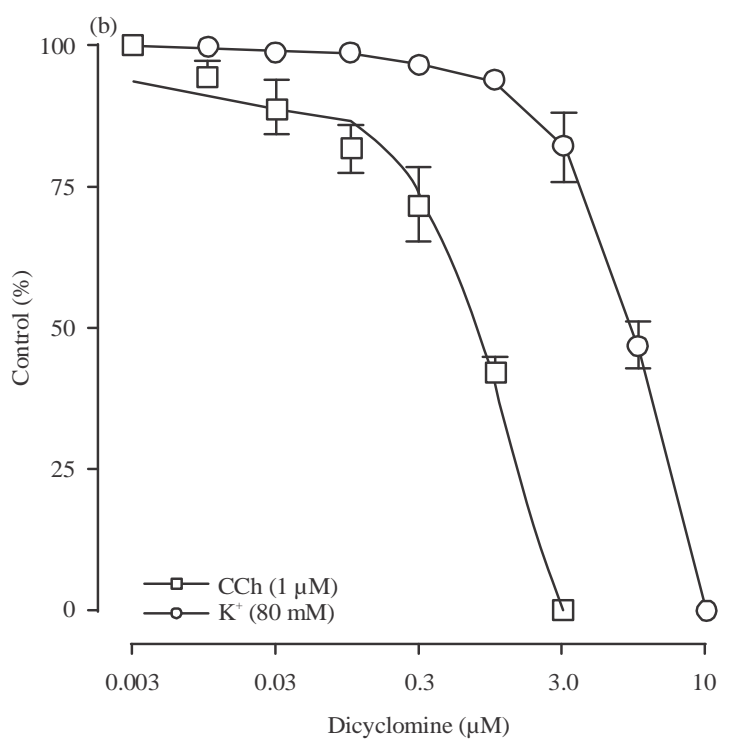

Fig. 3(a-b): Concentration-dependent inhibitory effect of (a) Crude extract of $P$. integerrima (Pi.Cr) and (b) Dicyclomine against CCh (carbachol, $1 \mu \mathrm{M})$ and high $\mathrm{K}^{+}(80 \mathrm{mM})$-induced contractions in isolated rabbit tracheal preparations. Values are expressed as Mean \pm SEM, $n=4-6$
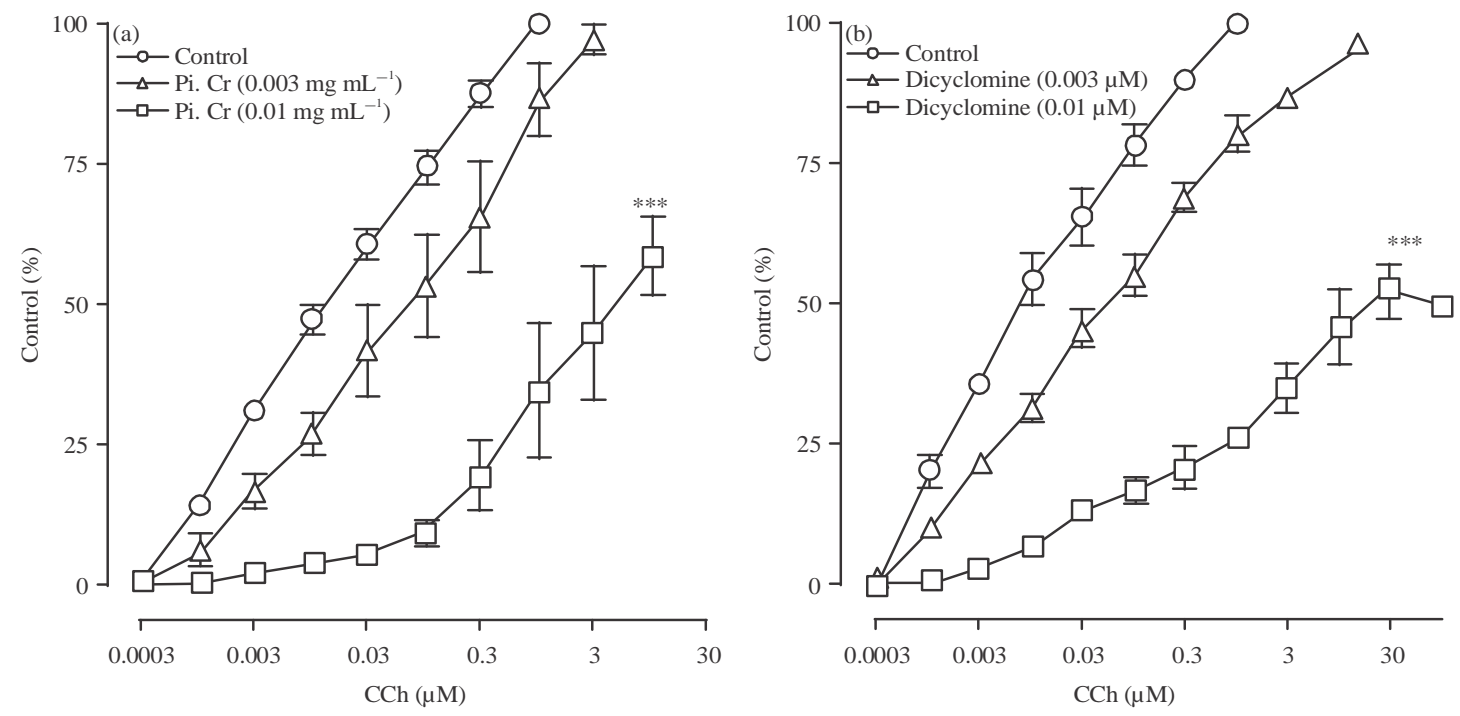

Fig. 4(a-b): Concentration-response curves of $\mathrm{Ca}^{++}$in the absence and presence of increasing doses of (a) Crude extract of $P$. integerrima (Pi.Cr) and (b) Dicyclomine in isolated rabbit tracheal preparations. Values are expressed as Mean \pm SEM, $n=3-5$ 
( $>0.05$ ) of the maximum response at lower dose $(0.003 \mu \mathrm{M})$, while at the concentration of $0.01 \mu \mathrm{M}$, it caused a rightward but non-parallel shift in the CCh curves with a marked suppression of the maximum effect $(51 \pm 2.11 \%, n=5)$ as shown in Fig. 4b.

\section{DISCUSSION}

The crude ethanolic extract of $P$. integerrima was subjected to pharmacological screening using the in vivo and in vitro assays, to validate its folkloric medicinal use in gastrointestinal and airway disorders. When tested on spontaneously contracting isolated rabbit jejunum preparations, the plant extract produced relaxation, indicating the possible presence of spasmolytic component(s), likely to produce decrease in propulsive activity through suppression of peristaltic movements. The spasmolytic activity observed in the in vitro experiments was confirmed in the in vivo experiments, where oral administration of the crude extract to mice produced antidiarrheal effect against castor oil-induced diarrhea, similar to the effect of loperamide, a known standard antidiarrheal agent (Reynolds et al., 1984). It has been observed that the spasmolytic action of the medicinal plants is usually mediated through $\mathrm{Ca}^{++}$channel blockade (Gilani et al., 2005, 2007; Khan et al., 2011; Janbaz et al., 2012; Bashir et al., 2013). $\mathrm{K}^{+}$at high doses $(>30 \mathrm{mM})$ is known to cause smooth muscle contractions through opening of voltage-dependent slow $\mathrm{Ca}^{++}$channels, thus allowing influx of extra cellular $\mathrm{Ca}^{++}$causing a contractile effect (Bolton, 1979; Godfraind et al., 1986). Hence, complete relaxation of high $\mathrm{K}^{+}$-induced spastic contractions by $\mathrm{Pi}$.Cr is suggestive of $\mathrm{Ca}^{++}$channel blockade (CCB)-like effect (Bolton, 1979). However, the high $\mathrm{K}^{+}$-induced contractions were relaxed at a higher dose (0.1-5 $\mathrm{mg} \mathrm{mL}^{-1}$ ) compared to its effect on spontaneous contractions, which might be because of the involvement of some other major inhibitory mechanism(s) in the spasmolytic behavior of Pi.Cr. Interestingly, muscarinic receptor antagonists are also known to produce partial inhibition in gut motility, as cholinergic innervations is one of the several mechanisms responsible for regulating intestinal movement (Galligan, 2002; Pasricha, 2005). Therefore, it can be speculated that antimuscarinic agent could be involved in spasmolytic activity of Pc.Cr. Carbachol (CCh) is a muscarinic agonist that can stimulate GI smooth muscle, increasing tone and motility of the muscle (Brown and Taylor, 2006). Pi.Cr exhibited complete relaxation of CCh-induced contractions at a lower doses than that of its effect against high $\mathrm{K}^{+}$and spontaneous contractions of isolated rabbit jejunum. This speculation was strengthened when the plant extract reversed both $\mathrm{CCh}$ and high $\mathrm{K}^{+}$-induced contractions, indicating the presence of at least two different spasmolytic mechanisms of action, similar to dicyclomine, a dual blocker of the muscarinic receptors and $\mathrm{Ca}^{++}$influx (Downie et al., 1977), is considered to be more efficacious spasmolytic, compared with pure anticholinergic agents (Brown and Taylor, 2006). Moreover, antimuscarinic agents if used alone through oral route, are likely to cause cardiac stimulation as a side effects (Brown and Taylor, 2006). The co-existence of $\mathrm{Ca}^{++}$antagonist constituent with antimuscarinic one is likely enhance the efficacy for its bronchodilator activity (acting through different target sites) as well as neutralize the cardiac side effects as the $\mathrm{Ca}^{++}$antagonists such as verapamil, are known to be cardiac suppressant (Hoffman, 2006).

For the confirmation of dual nature of inhibitory effect on the part of $P$. integerrima, CCh ConcentrationResponse Curves (CRCs) were constructed in the presence and absence of different doses of plant extract. The plant extract at a low dose caused a right ward parallel shift in CRCs of CCh without suppression of the maximum response, a typical characteristic of specific antagonist (Arunlakshana and Schild, 1959) however, at next higher dose, it caused a non-parallel shift with suppression of a maximum effect, pointing towards an additional non-competitive inhibition, as expected from a $\mathrm{Ca}^{++}$antagonists (Godfraind et al., 1986), similar to the behavior of dicyclomine against CRCs of CCh, which is known to be dual inhibitor of muscarinic receptors and $\mathrm{Ca}^{++}$influx (Downie et al., 1977).

The plant has also been traditionally used to treat airway disorders, such as asthma. Interestingly, $\mathrm{Ca}^{++}$ antagonists have been found useful in such disorders (Twiss et al., 2002). Antimuscarinics are also one of the major treatment modalities used for relief from asthma and bronchitis as the parasympathetic nervous system plays a major role in regulating bronchomotor tone (Barnes and Hansel, 2004).

Possible bronchodilator activity of the crude ethanolic extract of $P$. integerrima was explored on CCh and high $\mathrm{K}^{+}$-induced contractions in isolated rabbit tracheal preparations. The plant exhibited relaxant effect against both $\mathrm{CCh}$ and high $\mathrm{K}^{+}$-induced contractions, being more potent against $\mathrm{CCh}$, similar to the effect of dicyclomine. Thus, suggesting the observed bronchodilatory activity of the plant extract possibly mediated through dual inhibition of muscarinic receptors and $\mathrm{Ca}^{++}$channels, similar to its effect as seen in jejunum preparations. These results were further confirmed when $P$. integerrima extract displaced the CRCs of CCh on tracheal tissues to the right in a parallel manner without suppression of the maximum response at lower dose $\left(0.003 \mathrm{mg} \mathrm{mL}^{-1}\right)$, while at the next higher dose of $0.01 \mathrm{mg} \mathrm{mL}^{-1}$, it produced a non-parallel shift with the suppression of the maximum response as seen its activity pattern on jejunum tissues. The presence of dual nature of antispasmodic constituents in the plant is probably meant 
by nature for the synergetic interaction and/or to offset the undesired response of either of these constituents when used alone at higher concentrations or for longer duration. These findings are also in line with the earlier studies highlighting the medicinal plants possessing combination of constituents with synergistic and/or sideeffects neutralizing potential (Gilani and Atta-ur-Rahman, 2005).

In summary, $P$. integerrima showed antidiarrheal, spasmolytic and bronchodilator activities mediated possibly through dual inhibition of muscarinic receptors and $\mathrm{Ca}^{++}$influx, which offers potential of synergistic interaction with side-effects neutralizing combination. Thus, this study not only provides scientific basis for the medicinal use of the plant in gut and airways disorders but also offers merit for this to be developed as phytopharmaceutical.

\section{ACKNOWLEDGMENT}

This study was carried out during electives of Mr. Waseem Hassan at the Department of Biological and Biomedical Sciences under supervision of Dr. Malik Hassan Mehmood and Professor Anwarul-Hassan Gilani, Aga Khan University, Karachi with partial financial support from the Higher Education Commission, Government of Pakistan.

\section{REFERENCES}

Ahmad, N.S., M. Farman, M.H. Najmi, K.B. Mian and A. Hasan, 2008. Pharmacological basis for use of Pistacia integerrima leaves in hyperuricemia and gout. J. Ethnopharmacol., 117: 478-482.

Ahmad, S., M. Ali, S.H. Ansari and F. Ahmed, 2010a. Phytoconstituents from the galls of Pistacia integerrima Stewart. J. Saudi Chem. Soc., 14: 409-412.

Ahmad, N.S., A. Waheed, M. Farman and A. Qayyum, 2010b. Analgesic and anti-inflammatory effects of Pistacia integerrima extracts in mice. J. Ethnopharmacol., 129: 250-253.

Ansari, S.H. and M. Ali, 1996. Analgesic and antiinflammatory activity of tetracyclic triterpenoids isolated from Pistacia integerrima galls. Fitoterapia, 67: 103-105.

Ansari, S.H., M. Ali and J.S. Qadry, 1993. Essential oils of Pistacia integerrima galls and their effect on the central nervous system. Pharmaceut. Biol., 31: 89-95.

Aqil, F. and I. Ahmad, 2003. Broad-spectrum antibacterial and antifungal properties of certain traditionally used Indian medicinal plants. World J. Microbiol. Biotechnol., 19: 653-657.

Arunlakshana, O. and H.O. Schild, 1959. Some quantitative uses of drug antagonists. $\mathrm{Br}$. J. Pharmacol. Chemother., 14: 48-58.
Barnes, P.J. and T.T. Hansel, 2004. Prospects for new drugs for chronic obstructive pulmonary disease. Lancet, 364: 985-996.

Bashir, S., S. Abbas, A. Khan and A.H. Gilani, 2013. Studies on bronchodilator and cardiac stimulant activities of Urginea indica. Bangladesh J. Pharmacol., 8: 249-254.

Bolton, T.B., 1979. Mechanism of action of transmitters and other substances on smooth muscles. Physiol. Rev., 59: 606-618.

Brown, J.H. and P. Taylor, 2006. Muscarinic Receptor Agonists and Antagonists. In: The Pharmacological Basis of Therapeutics, Brunton, L.L., J.S. Lazo and K.L. Parker (Eds.). 11th Edn., McGraw-Hill, New York, USA., pp: 183-200.

Downie, J.W., D.A. Twiddy and S.A. Awad, 1977. Antimuscarinic and noncompetitive antagonist properties of dicyclomine hydrochloride in isolated human and rabbit bladder muscle. J. Pharmacol. Exp. Therapeut., 201: 662-668.

Galligan, J.J., 2002. Pharmacology of synaptic transmission in the enteric nervous system. Curr. Opin. Pharmacol., 2: 623-629.

Gilani, A.H. and Atta-ur-Rahman, 2005. Trends in ethnopharmocology. J. Ethnopharmacol., 100: 43-49.

Gilani, A.H., A. Khan, F. Subhan and M. Khan, 2005. Antispasmodic and bronchodilator activities of St John's wort are putatively mediated through dual inhibition of calcium influx and phosphodiesterase. Fundam. Clin. Pharmacol., 19: 695-705.

Gilani, A.H., S. Bashir and A.U. Khan, 2007. Pharmacological basis for the use of Borago officinalis in gastrointestinal, respiratory and cardiovascular disorders. J. Ethnopharmacol., 114: 393-399.

Godfraind, T., R. Miller and M. Wibo, 1986. Calcium antagonism and calcium entry blockade. Pharmacol. Rev., 38: 321-416.

Hoffman, B.B., 2006. Therapy of Hypertension. In: Goodman and Gilman's the Pharmacological Basis of Therapeutics, Brunton, L.L., J.S. Lazo and K.L. Parker (Eds.).11th Edn., McGraw-Hill, New York, ISBN: 9780071608916, pp: 845-868.

Janbaz, K.H., U. Zia, M.H. Mehmood, S. Bashir, M.I. Choudhary and A.H. Gilani, 2012. Antiinflammatory, free radical scavenging and calcium antagonist activities of Corchorus fascicularis Lam. crude extract. J. Anim. Plant Sci., 22: 954-959.

Khan, A., Q.J. Khan and A.H. Gilani, 2011. Pharmacological basis for the medicinal use of cardamom in asthma. Bangladesh J. Pharmacol., 6: 34-37.

Khan, M., N. Rehman, A. Khan and A.H. Gilani, 2012. Pharmacological basis for the medicinal use of Morus alba in gut and airways disorders. Bangladesh J. Pharmacol., 7: 289-298. 
Mandukhail, S.R., A.F. Ahmed, H.M. Al-Yousef, J.H. Al-Qahtani and A.H. Gilani, 2014. The mechanism underlying the spasmolytic and bronchodilatory activities of the flavonoid-rich red onion Allium cepa L. peel extract. Int. J. Pharmacol., 10: 82-89.

Mehmood, M.H. and A.H. Gilani, 2010. Pharmacological basis for the medicinal use of black pepper and piperine in gastrointestinal disorders. J. Med. Food, 13: 1086-1096.

Mehmood, M.H., H.S. Siddiqi and A.H. Gilani, 2011. The antidiarrheal and spasmolytic activities of Phyllanthus emblica are mediated through dual blockade of muscarinic receptors and $\mathrm{Ca}^{2+}$ channels. J. Ethnopharmacol., 133: 856-865.

NRC., 1996. Guide for the Care and Use of Laboratory Animals. National Academy Press, Washington, DC., ISBN-13: 9780309053778, pp: 1-7.

Nadkarni, K.M., 1986. Indian Materia Medica. Popular Parkashan, Bombay, India, pp: 1062-1063.

Pant, S. and S.S. Samant, 2010. Ethanobotanical observations in the Mornaula reserve forest of Koumoun, West Himalaya. India Ethanobotanical Leaflets, 14: 93-217.

Pasricha, P.J., 2005. Treatment of Disorders of Bowel Motility and Water Flux. In: Goodman and Gilman's The Pharmacological Basis of Therapeutics, Brunton, L., J. Lazo and K. Parker (Eds.). 11th Edn., McGrawHill, New York, USA., ISBN-13: 9780071608916, pp: 983-1008.
Reynolds, I.J., R.J. Gould and S.H. Snyder, 1984. Loperamide: Blockade of calcium channels as a mechanism for antidiarrheal effects. J. Exp. Pharmacol. Ther., 231: 628-632.

Twiss, M.A., E. Harman, S. Chesrown and L. Hendeles, 2002. Efficacy of calcium channel blockers as maintenance therapy for asthma. Br. J. Clin. Pharmacol., 53: 243-249.

Uddin, G. and A. Rauf, 2012. In vitro antimicrobial profile of Pistacia integerrima Galls Stewart. Middle-East J. Med. Plants Res., 1: 36-40.

Uddin, G., A. Rauf, M. Arfan, Waliullah and I. Khan et al., 2012a. Pistagremic acid a new leishmanicidal triterpene isolated from Pistacia integerrima Stewart. J. Enzyme Inhib. Med. Chem., 27: 646-648.

Uddin, G., A. Rauf, A.M. Al-Othman, S. Collina, M. Arfan, G. Ali and I. Khan, 2012b. Pistagremic acid, a glucosidase inhibitor from Pistacia integerrima. Fitoterapia, 83: 1648-1652.

Usmanghani, K., A. Saeed and M.T. Alam, 1997. Indusyunic Medicine: Traditional Medicine of Herbal, Animal and Mineral Origin in Pakistan. University of Karachi Press, Karachi, Pages: 591. 